\title{
PERSEPSI IBU TERHADAP BERBAGAI MODEL GENDONGAN PERAWATAN METODE KANGURU (PMK): PILOT STUDY
}

\author{
Sholihatul Amaliya ${ }^{1}$, Yeni Rustina ${ }^{2}$, Nur Agustini ${ }^{2}$ \\ 1. Jurusan Keperawatan, Fakultas Kedokteran, Universitas Brawijaya liya.fk.psik@ub.ac.id; \\ sholihatulamaliya@gmail.com \\ 2. Fakultas Ilmu Keperawatan Universitas Indonesia, Depok, Jawa Barat, y_rustina@ui.ac.id \\ 3.
}

\begin{abstract}
ABSTRAK
Latar belakang: Pelaksanaan Perawatan Metode Kanguru (PMK) di Indonesia telah berkembang dengan baik. Hal ini dibuktikan dengan telah dimasukkannya PMK menjadi salah satu prosedur tetap dalam perawatan bayi berat lahir rendah (BBLR) pada banyak rumah sakit di Indonesia. Satu-satunya alat yang dibutuhkan dalam pelaksanaan PMK yaitu gendongan PMK. Model gendongan PMK yang banyak digunakan di Indonesia yaitu model Kantong, Thari dan Kain Panjang.

Tujuan: Penelitian ini bertujuan untuk mengidentifikasi persepsi ibu terhadap tiga model gendongan PMK dan mengidentifikasi hubungan kecemasan ibu dan tingkat ekonomi terhadap persepsi ibu tentang gendongan PMK.
\end{abstract}

Metode : Penelitian ini merupakan uji klinis dengan menggunakan metode Randomized Crossover Trial yang melibatkan 20 responden ibu dan BBLR. Sampel dilakukan randomisasi alokasi untuk mendapatkan intervensi PMK dengan menggunakan gendongan kantong, gendongan thari dan kain panjang. Data persepsi dan kecemasan ibu dikumpulkan dengan menggunakan kuesioner persespsi ibu dan kuesioner Am I Blue. Tingkat ekonomi ibu juga dikaji dengan mengkaji penghasilan dalam keluarga. Hasil: Hasil analisis menggunakan Repeated Anova menunjukkan bahwa tidak ada perbedaan bermakna persepsi ibu terhadap tiga jenis model gendongan PMK $(\mathrm{p}=0,504, \alpha=0,05)$. Selain itu juga terdapat hubungan yang bermakna skor kecemasan ibu dan tingkat ekonomi terhadap persepsi tentang tiga model gendongan PMK ( $\mathrm{p}=0,021$ dan $\mathrm{p}=0,003)$.

Kesimpulan: Jenis model gendongan PMK tidak mempengaruhi persepsi ibu, sehingga pelaksanaan perawatan metode kanguru dapat menggunakan ketiga jenis model gendongan tersebut.

Kata kunci: gendongan PMK; bayi berat lahir rendah; persepsi ibu; kecemasan ibu

\section{ABSTRACT}

Background: The implementation of the Kangaroo Care Method (KMC) in Indonesia has been well developed. This has been proven by the inclusion of KMC as one of the standard procedures in the care of low birth weight (LBW) babies in many hospitals in Indonesia. The only one tool needed in implementing KMC is KMC carriers. The most widely used KMC carriers models in Indonesia are the pouch (bag), Thari wrap and traditional wrap models.

Objective: This study aims are to identify mothers' perceptions of three different types of KMC carrier models and to identify the relationship of maternal anxiety and economic level to the perception of mothers about KMC carriers

Method: The study used Randomized Crossover Trial involving 20 mothers and LBW infants as responders and randomly allocated to the order of KMC using three kinds of KMC carriers. Data maternal perception were collected using a maternal perception questionnaire and maternal anxiety using Am I Blue questionnaire.

Result: The results of a Repeated Anova showed that there was no significant difference in maternal perception when performing KMC with any of three KMC carriers $(p=0.504, \alpha=0.05)$. There is also a significant relationship between maternal anxiety scores and economic levels on perceptions of the three KMC carrier models ( $p=0,021$ and $p=0,003)$.

Conclusion: The type of KMC carrier model did not affect the perception of the mother so that the implementation of kangaroo mother care can use all three types of KMC carriers models.

Keyword: KMC carriers, low birth weight, maternal perception, maternal anxiety 


\section{PENDAHULUAN}

Insiden terjadinya bayi berat lahir rendah (BBLR) di seluruh dunia menurut data UNICEF (2013) yaitu sebesar 22 juta atau 16\% dari seluruh jumlah kelahiran hidup setiap tahun di seluruh dunia (WHO, 2014). Di Indonesia, prevalensi BBLR sebesar 10,2\% dimana terjadi penurunan dari tahun sebelumnya yaitu 2010 sebesar 11,1\%. Akan tetapi angka ini masih tergolong tinggi dibandingkan dengan beberapa negara Asia Tenggara (Kemenkes RI, 2015).

BBLR memiliki risiko lebih tinggi mengalami morbiditas dan mortalitas dibandingkan dengan bayi normal. Hal ini berhubungan dengan kondisi berat badan yang rendah saat lahir serta kondisi sistem yang belum sempurna, karena mayoritas BBLR dilahirkan dalam usia kurang dari 37 minggu (Bera et al., 2014). Kelahiran berat bayi lahir rendah (BBLR) merupakan penyebab kematian utama pada bayi baru lahir (Akhtar, Haque, \& Khatoon, 2013). Salah satu masalah yang dialami oleh BBLR yaitu masalah termoregulasi yang disebabkan imuturitas sistem dan kondisi lingkungan yang relatif lebih dingin dibandingkan dengan kondisi dalam rahim (Cho et al., 2016). Gangguan termoregulasi dan lingkungan yang lebih dingin berisiko menyebabkan hipotermia (Knobel \& Holditch-Davis, 2007). Hipotermia yang terjadi dapat menyebabkan hipoksia, komplikasi kardiovaskular, hipoglikemia dan asidosis yang meningkatkan risiko morbiditas dan mortalitas (Knobel, 2014) (Lunze \& Hamer, 2012).

Idealnya perawatan bayi prematur menggunakan inkubator sehingga dapat diatur suhu dan kelembapan udara yang sesuai untuk bayi BBLR atau bayi prematur yang memilki sistem termoregulasi yang masih imatur. Akan tetapi tidak semua BBLR terutama pada daerah dengan kondisi ekonomi terbatas serta kondisi geografis yang jauh dari pusat pelayanan kesehatan bisa menerima fasilitas inkubator. Oleh karena itu diperlukan alternatif perawatan BBLR yang efektif dan ekonomis sebagai pengganti inkubator yaitu dengan menggunakan perawatan metode kanguru (PMK).

Perawatan Metode Kanguru (PMK) atau Perawatan Bayi Lekat (PBL) adalah suatu metode perawatan bayi baru lahir dalam keadaan telanjang (hanya menggunakan popok dan topi) dengan meletakkan bayi secara tegak atau vertikal diantara kedua payudara ibu (ibu telanjang dada) kemudian diselimuti sehingga terjadi kontak langsung kulit ibu dengan kulit bayi dan bayi memperoleh suhu dari ibu melalui proses konduksi (Arora, 2008). Idealnya PMK dilakukan hingga berat bayi mencapai 2500 gram, saat usia koreksi mencapai 40 minggu atau hingga bayi tidak nyaman lagi dilakukan PMK (Pervin, Gustafsson, Moran, \& Roy, 2015).

Perawatan BBLR dengan menggunakan PMK telah berkembang dengan baik di Indonesia. Hal ini dibuktikan dengan telah dimasukkannya PMK menjadi salah satu prosedur tetap pada 34 Copyright @ 2019, JKM, p-ISSN 2088-6098, e-ISSN 2550-0538 
perawatan bayi berat lahir rendah (BBLR) pada banyak rumah sakit di Indonesia. Selain itu, kini juga telah banyak berkembang model gendongan PMK yang merupakan satu-satunya alat yang dibutuhkan dalam melakukan PMK. Model gendongan PMK yang banyak digunakan di rumah sakit Indonesia yaitu model kantong, thari dan menggunakan kain panjang. Tujuan penelitian ini yaitu untuk mengidentifikasi persepsi ibu terhadap tiga jenis gendongan PMK. Hasil primer adalah teridentifikasi perbandingan persepsi ibu saat dilakukan PMK dengan menggunakan tiga jenis gendongan PMK yaitu model kantong, thari dan kain panjang. Hasil sekunder adalah untuk mengidentifikasi korelasi antara kecemasan ibu, durasi PMK dan tingkat ekonomi terhadap persepsi ibu tentang tiga jenis gendongan PMK.

\section{METODE}

\section{Desain Penelitian}

Penelitian ini merupakan uji klinis dengan menggunakan metode Randomized Crossover Trial yang melibatkan 20 respoden ibu dan bayi dengan berat lahir rendah (BBLR). Intervensi dalam penelitian ini terdiri dari penggunaan PMK dengan gendongan kantong (A), PMK dengan gendongan Thari (B) dan PMK dengan kain panjang (C). Urutan dari tiga intervensi dalam penelitian ini dilakukan dengan skema counterbalancing sehingga dihasilkan enam macam urutan intervensi yaitu ABC, ACB, BCA, BAC, CAB, CBA (Stommel \& Wills, 2004). Selanjutnya dilakukan randomisasi alokasi menggunakan amplop tertutup untuk menentukan urutan yang diperoleh untuk setiap sampel. Periode washout antar intervensi adalah minimal 3 jam.

\section{Tempat Penelitan}

Penelitian dilakukan pada bulan Mei hingga Juni tahun 2017 di dua rumah sakit Jakarta yaitu RSUP Fatmawati dan RSPAD Gatot Subroto. Penelitian dilakukan setelah memperoleh persetujuan dari komite Komisi Etik Fakultas Ilmu Keperawatan, Universitas Indonesia (No.123/UN2.F12.D/HKP.02.04/2017), izin dari RSUP Fatmawati (DM 03.01/II.3/1307/2017), RSPAD Gatot Soebroto (B/2360/V/2017) dan persetujuan tertulis dari responden.

\section{Populasi dan Sampel}

Populasi terjangkau pada penelitian ini yaitu ibu dan bayi berat lahir rendah yang dirawat di rumah sakit di Jakarta, sedangkan sampel pada penelitian ibu dan bayi berat lahir rendah 
yang dirawat di RSUP Fatmawati dan RSPAD Gatot Subroto yang dipilih dengan menggunakan consecutive sampling. Menurut Hertzog (2008) jumlah sampel untuk sebuah pilot study adalah 10-40, oleh karena itu jumlah sampel pada penelitan ini adalah 22 ibu dan bayi, namun 2 responden drop out sehingga total sampel pada penelitian ini adalah 20 ibu dan bayi berat lahir rendah.

\section{Kriteria Inklusi dan Eksklusi}

Kriteria inklusinya yaitu ibu dengan BBLR yang dirawat di dua rumah sakit tersebut, bisa membaca dan menulis menulis, ibu bersedia melakukan PMK dan bayi dengan kondisi hemodinamik stabil. Kriteria eksklusinya ibu dengan infeksi dan penyakit kulit, ibu hanya melakukan PMK dengan 1 atau 2 jenis gendongan PMK, bayi dengan kelainan hipotalamus dan bayi terpasang alat bantu napas invasif.

\section{Instrumen Penelitian}

Alat pengumpulan data yang digunakan dalam penelitian ini adalah kuesioner persepsi ibu dan kecemasan ibu. Kuesioner persepsi ibu merupakan kuesioner dengan skala likert yang terdiri dari 8 pernyataan yang telah dilakukan uji validitas dan semua item pernyataan tersebut telah dinyatakan valid. Selanjutnya dilakukan uji reliabilitas dan didapatkan hasil bahwa kuesioner tersebut reliabel dengan nilai cronbach alpha 0,744. Kuesioner kecemasan ibu menggunakan kuesioner baku yaitu "Am I Blue" yang telah digunakan pada penelitian sebelumnya.

\section{Prosedur Penelitian}

Sebelum melakukan PMK, ibu diberikan edukasi tentang PMK yang terdiri dari pengertian, manfaat, prosedur dan jenis gendongan PMK. Selain itu ibu akan diminta untuk mengisi kuesioner kecemasan ibu dan dikaji data demografinya. Saat melakukan PMK ibu diminta menggunakan baju dengan kancing depan dan bayi hanya menggunakan diapers, topi dan sarung tangan. Selanjutnya ibu akan dilakukan PMK dengan gendongan tertentu (kantong, thari dan kain panjang) sesuai dengan urutan intervensi. Selanjutnya dilakukan randomisasi alokasi untuk menentukan urutan intervensi bagi masing-masing responden dengan menggunakan amplop tertutup. Selama dilakukan PMK kondisi bayi tetap dalam pemantauan peneliti. Periode washout antar intervensi adalah minimal 3 jam. Setelah selesai setiap kali intervensi ibu akan diminta mengisi kuesioner tentang persepsi ibu terhadap gendongan PMK 
dan pada akhir intervensi ibu diminta untuk menentukan pilihan gendongan PMK yang menurut ibu paling nyaman.

Analisis data yang digunakan yaitu uji Repeated Anova untuk menguji persepsi ibu, uji Pearson untuk menganalisis hubungan antara skor kecemasan ibu dengan persepsi ibu, dan Anova untuk menganalisis hubungan level ekonomi dengan persepsi ibu tentang gendongan PMK dengan tingkat signifikan yang ditetapkan sebesar $\mathrm{p}<0,05$.

\section{HASIL}

\section{Karakteristik Responden}

Hasil penelitian berupa karakteristik dasar responden ditampilkan pada tabel 1. Rerata bayi yang dilakukan PMK memiliki berat lahir 1771 gram dan berat badan saat dilakukan penelitian sebesar 1841 gram. Rerata usia ibu yang melakukan PMK adalah 30,95 tahun dengan usia gestasi 33 minggu serta skor kecemasan ibu 15,05. Sebagian besar ibu merupakan primipara (55\%), pendidikan terakhir SMA (65\%) dan berpenghasilan rata-rata Rp. 2.500 .000 - Rp. 3.500.000.

\section{Perbandingan Persepsi Ibu}

Hasil uji bivariat (tabel 2) menunjukkan tidak berbeda secara bermakna persepsi ibu saat melakukan PMK dengan tiga jenis gendongan PMK model kantong, thari dan kain panjang. Hasil analisis juga menyatakan bahwa tidak ada hubungan antara durasi PMK terhadap persepsi ibu tentang jenis gendongan PMK. Akan tetapi skor kecemasan ibu dan tingkat ekonomi berpengaruh terhadap persepsi ibu tentang jenis gendongan PMK. hasil tambahan pada penelitian ini yaitu tentang prosentase pilihan jenis gendongan. Pada gambar 3 terlihat bahwa mayoritas ibu memilih gendongan jenis kantong, selanjutnya adalah gendongan kain panjang dan terakhir adalah gendongan thari.

\section{PEMBAHASAN}

Berat badan lahir bayi yang dilakukan PMK pada penelitian ini memiliki rerata 1771 gram yang masuk dalam kategori low birth weight (LBW). Berat badan merupakan salah satu kriteria untuk bisa dilakukan PMK selain kondisi hemodinamik yang stabil (WHO, 2003). Bayi dengan berat badan lebih dari 1800 gram pada umumnya dalam kondisi stabil saat lahir dan sebagian besar bayi-bayi tersebut dapat dilakukan PMK. Sementara itu bayi dengan berat badan 1200-1799 gram biasanya memiliki beberapa masalah kesehatan saat lahir, sehingga perlu beberapa hari stabilisasi di ruang perawatan khusus baru dapat dilakukan PMK. Selanjutnya bayi dengan berat badan kurang dari 1200 gram sering mengalami masalah kesehatan yang berisiko menyebabkan kematian segera setelah lahir, sehingga perlu perawatan di fasilitas 
perawatan intensive selama beberapa hari hingga beberapa minggu (Neonatal Division, AIIMS, 2004). Oleh karena itu inisiasi pelaksanaan PMK ditentukan oleh kondisi hemodinamik bayi. Bayi dengan kondisi hemodinamik stabil saat dilahirkan dapat segera dilakukan PMK; sedangkan bayi dengan masalah kesehatan saat lahir perlu beberapa hari hingga beberapa minggu di ruang perawatan khusus hingga kondisi hemodinamik stabil dan bisa dilakukan PMK. Bayi dengan usia gestasi dan berat badan lahir yang lebih tinggi maka akan dapat dilakukan PMK lebih dini dibandingkan dengan bayi dengan usia gestasi dan berat badan lahir yang lebih kecil (Blomqvist, 2012).

Persepsi ibu tentang gendongan PMK yang dinilai dalam penelitian ini terdiri dari kemudahan dalam memasang, kemudahan dalam mendapatkan (harga terjangkau dan mudah didapatkan), memfasilitasi menyusui dan kemampuan mempertahankan bayi pada dada ibu. Kemampuan gendongan PMK untuk memfasilitasi menyusui dan mempertahankan bayi pada dada ibu sesuai dengan karakteristik gendongan PMK yang diisyaratkan oleh WHO (WHO, 2003). Dari hasil penelitian ini didapatkan tidak terdapat perbedaan signifikan persepsi ibu tentang gendongan kantong, thari ataupun kain panjang. Hal ini menunjukkan bahwa ketiga jenis gendongan PMK tersebut memenuhi kriteria yaitu mudah digunakan, mudah didapat dengan harga terjangkau, memfasilitasi menyusui dan dapat mempertahankan bayi di dada ibu.

Manfaat PMK alam memfasilitasi bayi untuk menyusu pada ibu dapat meningkatkan angka menyusui (Sarparast \& Farhadi, 2015). Selain itu fungsi gendongan PMK untuk mempertahankan bayi di dada ibu dan memastikan kulit bayi menempel pada kulit ibu sangat penting karena hal ini dapat menimbulkan terjadinya maternal neonatal thermal synchrony yaitu perubahan suhu pada payudara ibu untuk mempertahankan suhu tubuh bayi normal (Jain \& Sarkar, 2000). Dengan demikian akan terjadi perpindahan panas secara konduksi dari ibu ke bayi sehingga bayi tetap hangat (Rustina, 2015). Selain untuk mempertahankan kondisi bayi tetap hangat, PMK juga dapat membantu menurunkan suhu tubuh bayi pada saat demam dengan karena terjadinya perpindahan panas dari kulit bayi ke kulit ibu (Hartini, 2011).

Skor kecemasan dari hasil analisis bivariate mempengaruhi persepsi ibu terhadap gendongan PMK yang dipakai. Kecemasan yang di alami ibu disebabkan oleh kondisi bayi dan perubahan peran orang tua (Saidah, Rustina, \& Nurhaeni, 2011). Kecemasan yang dialami ibu dapat mempengaruhi lapang pandang ibu, sehingga dapat mempengaruhi persepsi ibu (Woo, Wasserman, \& Chang, 2012). Hal ini dapat memberikan pengaruh pada ibu dalam menilai jenis gendongan PMK yang dipakai. Tingkat perekonomian yang berbeda juga mempengaruhi persepsi ibu tetang jenis gendongan PMK, karena ketiga jenis gendongan tersebut memiliki 
harga yang berbeda. Gendongan PMK model kantol harganya Rp.75.000,00, thari Rp. 60.000,00, sedangkan kain panjang Rp. 55.000,00. Selain harga, factor lain yang mempengaruhi yaitu ketersediaan gendongan tersebut. Gendongan kantong dan thari perlu dibeli terlebih dahulu agar bisa digunakan, sedangkan kain panjang ketersediaannya lebih banyak di masyarakat dan bisa diperoleh lebih mudah, bahkan tanpa membeli dengan memanfaatkan kain panjang yang mayoritas dimiliki oleh ibu yang pernah melahirkan sebelumnya. Pilihan responden terhadap jenis gendongan PMK dapat dilihat pada gambar 3.

\section{SIMPULAN}

Tidak terdapat perbedaan bermakna persepsi ibu terhadap tiga jenis gendongan PMK yaitu model kantong, thari dan kain panjang. Faktor yang berpengaruh terhadap persepsi ibu adalah skor kecemasan ibu dan tingkat ekonomi. Oleh karena itu ketiga jenis gendongan ini dapat digunakan untuk melaksanakan PMK, namun disesuaikan dengan kondisi ekonomi keluarga. Hasil penelitian ini dapat dijadikan data dasar untuk melakukan penelitian selanjutnya tentang gendongan PMK, mengingat penelitian ini merupakan pilot study sehingga dimungkinkan ada penelitian-penelitian selanjutnya mengenai gendongan PMK yang banyak digunakan di rumah sakit Indonesia.

\section{KETERBATASAN PENELITIAN}

Pada penelitian ini, peneliti tidak dapat menyeragamkan durasi waktu pelaksanaan PMK, hal ini disebabkan ada beberapa kondisi kesehatan bayi yang tidak dimungkinkan untuk dilakukan PMK selama satu jam. Penelitian selanjutnya diharapkan untuk meneliti juga tentang persepsi perawat atau petugas kesehatan lain tentang gendongan PMK yang sesuai digunakan dalam fasilitas pelayanan kesehatan.

\section{UCAPAN TERIMAKASIH}

Peneliti mengucapkan terima kasih kepada RSUP Fatmawati, RSPAD Gatot Subroto atas izin penelitian yang telah diberikan, responden yang turut serta dalam penelitian serta Program Studi Ilmu Keperawatan (PSIK) Universitas Brawijaya, Malang yang telah mendukung proses penelitian.
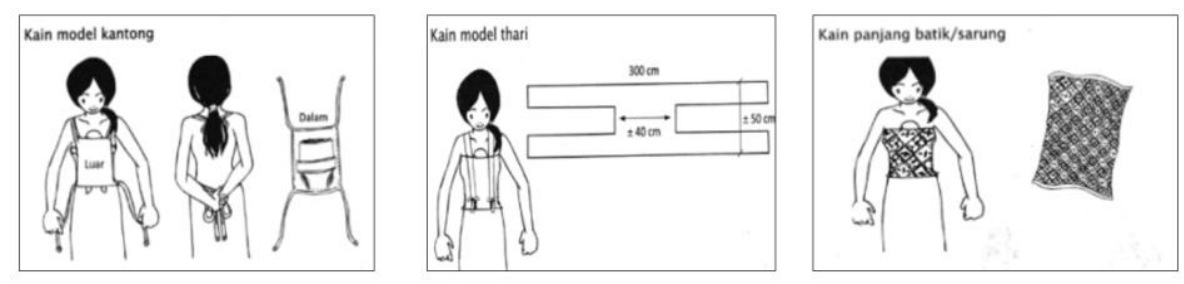

Gambar 1. Gendongan Kantong, Gendongan Thari dan Kain Panjang 


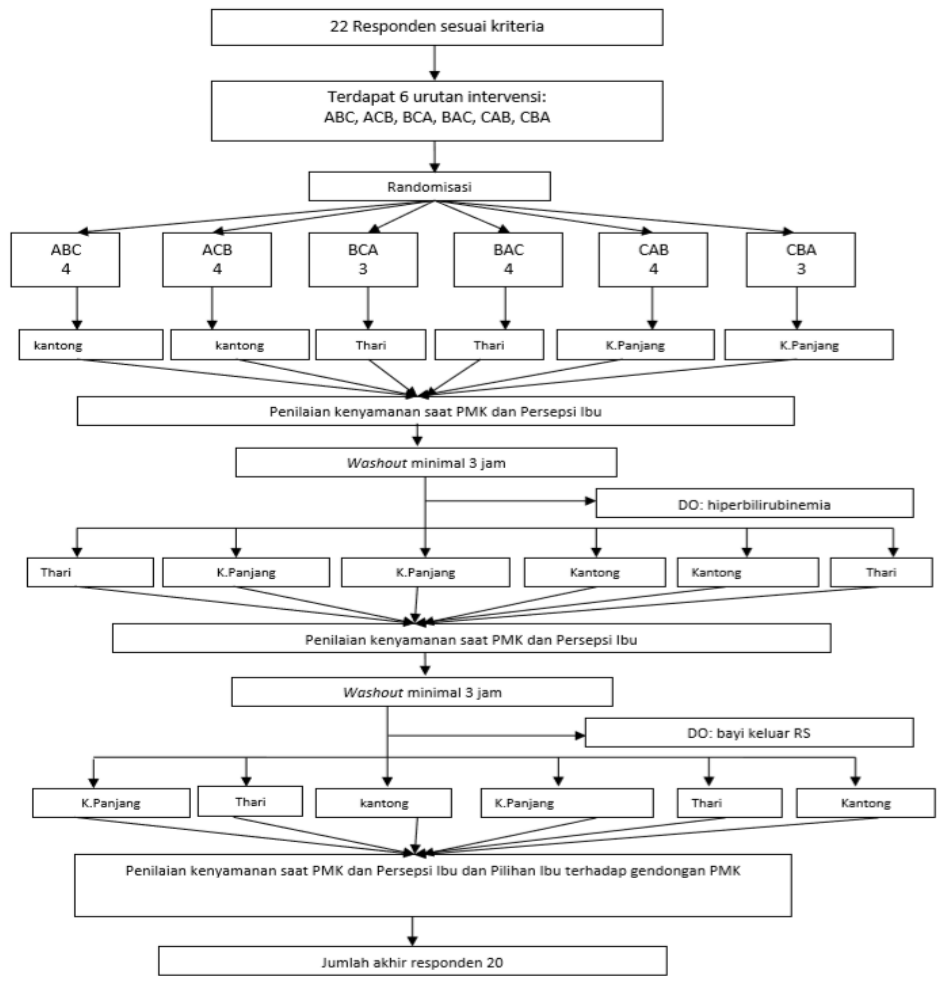

Gambar 2. Diagram Rekrutmen dan Alokasi responden

Tabel 1. Karakteristik BBLR dan Ibu (20)

\begin{tabular}{|c|c|c|}
\hline Variabel & Mean (SD) & $\%$ \\
\hline Berat Badan Lahir & $1771 \pm 323,92$ & \\
\hline Berat Badan Saat & 1841.75 & \\
\hline Penelitian & \pm 194.85 & \\
\hline Usia Ibu & $30,95+6,9$ & \\
\hline Usia Gestasi & $33 \pm 2,5$ & \\
\hline Skor Kecemasan Ibu & $15,05 \pm 8,1$ & \\
\hline \multicolumn{2}{|l|}{ Riwayat Melahirkan } & \\
\hline Iya & & \\
\hline Tidak & & 55 \\
\hline \multirow{2}{*}{\multicolumn{3}{|c|}{ Tingkat Pendidikan }} \\
\hline & & 10 \\
\hline SMP & & 20 \\
\hline SMA & & \\
\hline \multirow{2}{*}{\multicolumn{3}{|c|}{ Tingkat Ekonomi }} \\
\hline & & \\
\hline$<1.500 .000$ & & \\
\hline $1.500 .000-2.500 .000$ & & 15 \\
\hline $2.500 .000-3.500 .000$ & & 60 \\
\hline $\begin{array}{l}<3.500 .000 \\
\text { Durasi PMK dengan }\end{array}$ & \multicolumn{2}{|c|}{ Durasi PMK dengan Gendongan } \\
\hline Kantong & & \\
\hline 45 menit $-<1$ jam & & 65 \\
\hline $1-<2$ jam & & 25 \\
\hline \multirow{2}{*}{\multicolumn{3}{|c|}{$\begin{array}{l}\geqslant 2 \text { lam } \\
\text { Durasi PMK dengan Gendongan }\end{array}$}} \\
\hline & & \\
\hline 45 menit $-<1$ jam & & 65 \\
\hline $1-<2$ jam & & 10 \\
\hline \multicolumn{3}{|c|}{ Durasi PMK dengan kain Panjang } \\
\hline & & \\
\hline $1-<2 \mathrm{jam}$ & & 80 \\
\hline
\end{tabular}

\section{Pilihan Jenis Gendongan PMK}

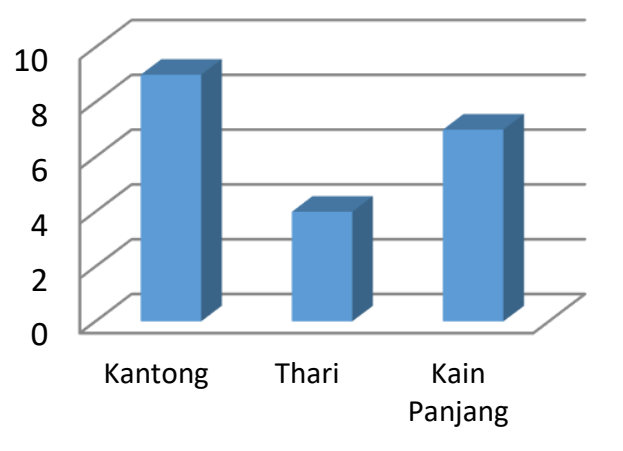

Gambar 3. Prosentase pilihan jenis Gendongan PMK

Tabel 2. Perbandingan skor kenyamanan dan persepsi Ibu

\begin{tabular}{lll}
\hline Kenyamanan dan Persepsi Ibu & Mean (SD) & p value \\
\hline Persepsi terhadap Kantong & $23,40 \pm 3,15$ & \\
\hline Persepsi terhadap Thari & $22,70 \pm 3,63$ & 0,504 \\
\hline Persepsi pada Kain Panjang & $22,20 \pm 2,44$ & \\
\hline
\end{tabular}

Tabel 3. Pengaruh skor kecemasan dan Durasi PMK terhadap Kenyamanan dan Persepsi

\begin{tabular}{lc}
\hline \multicolumn{1}{c}{ Variabel } & Persepsi \\
\hline Skor Kecemasan & $\mathrm{r}=-0,297$ \\
& $\mathrm{p}=0,021$ \\
\hline Variabel & Persepsi \\
\hline Tingkat Ekonomi & $\mathrm{p}$ value $(0,003)$ \\
$<1.500 .000$ & \\
$1.500 .000-2.500 .000$ & \\
$2.500 .000-3.500 .000$ & \\
$<3.500 .000$ & \\
\hline
\end{tabular}

\section{DAFTAR PUSTAKA}

Akhtar, K., Haque, M., \& Khatoon, S. (2013). Kangaroo Mother Care: A Simple Method to Care for Low-Birth-Weight Infants in Developing Countries. Journal of Shaheed Suhrawardy Medical College, 5(1), 49-54. https://doi.org/10.3329/jssmc.v5i1.16256

Bera, A., Ghosh, J., Singh, A. K., Hazra, A., Mukherjee, S., \& Mukherjee, R. (2014). Effect of kangaroo mother care on growth and development of low birthweight babies up to 12 months of age : A controlled clinical trial. Acta Paediatrica, 103, 643-650. https://doi.org/10.1111/apa.12618 
Jain, P. K., \& Sarkar, D. (2000). Physiological effects of kangarooing on the newborns weighing less than 2000 grams. International Journal of Basic and Applied Physiology, 4(1), 113-117.

Lunze, K., \& Hamer, D. H. (2012). Thermal protection of the newborn in resource-limited environments. Journal of Perinatology, 32(5), 317-324. https://doi.org/10.1038/jp.2012.11

Cho, E. S., Kim, S., Kwon, M. S., Cho, H., Hye, E., Msn, K., ... Lee, S. (2016). The Effects of Kangaroo Care in the Neonatal Intensive Care Unit on the Physiological Functions of Preterm Infants , Maternal - Infant Attachment , and Maternal Stress. Journal of Pediatric Nursing, 31(4), 430-438. https://doi.org/10.1016/j.pedn.2016.02.007

Knobel, R \& Holditch-Davis, D. (2007). Thermoregulation and Heat Loss Prevention After Birth and During Neonatal Intensive-Care Unit Stabilization of Extremely LowBirthweight Infants. J Obstet Gynecol Neonatal Nurs, 36, 280-287. doi: 10.1111/J.1552-6909.2007.00149.x

All India Institute of Medical Sciences (AIIMS). (2013). Essential newborn nursing for small hospital: In source restricted countries, Learner's guide. (1st ed.). New Delhi: Noble Vision. Diperoleh dari: https://www.newbornwhocc.org/pdf/learner's_guide\%20-India.pdf

Asih, S. H., Wanda, D., Widyatuti, \& Rustina, Y. (2013). Pengaruh perawatan metode kangguruterhadap suhu tubuh bayi yang mengalami demam. Jurnal Ilmu Keperawatan dan Kebidanan, 1(9), 505-515.

Pervin, J., Gustafsson, F. E., Moran, A. C., \& Roy, S. (2015). Implementing Kangaroo mother care in a resource-limited setting in rural Bangladesh. Acta Paediatrica, 458-465. https://doi.org/10.1111/apa.12929

Kemenkes, RI. (2015). Indonesian Health Statistics 2014. (Vol. 51). https://doi.org/10.1037/0022-3514.51.6.1173

Saidah, Q. I., Rustina, Y., \& Nurhaeni, N. (2011). Penurunan Kecemasan Ibu Dan Perbaikan Status Bangun-Tidur Bblr Melalui Perawatan Metode Kanguru. Jurnal Keperawatan Indonesia, 14(3), 193-198.

Sarparast, L., \& Farhadi, R. (2015). The Effect of Kangaroo Mother Care on Neonatal Outcomes in Iranian Hospitals : A Review, J Pediatr Rev, 3(1), 1-9. https://doi.org/10.5812/jpr.195

World Health Organization. (2003). Kangaroo mother care: A practical guide. Journal of Tropical Pediatrics, 59(1), 1-2. https://doi.org/10.1093/tropej/fmt007

WHO. (2014). Global Nutrition Targets 2025 - Low Birth Weight Policy Brief. WHO_NMH_NHD_14.5_eng.Pdf, 4(5737), 745. https://doi.org/10.1136/bmj.4.5737.745$\mathrm{b}$

Woo, H., Wasserman, R. C., \& Chang, Y. (2012). NIH Public Access. American Journal of Preventative Medicine, 43(5), 533-536. https://doi.org/10.1016/j.amepre.2012.07.020.Pediatrician 